\title{
All authors must now supply ORCID identifiers
}

\author{
C. Barry Carter ${ }^{1,2, *} \oplus$ and Christopher F. Blanford ${ }^{3} \oplus$ \\ ${ }^{1}$ Department of Materials Science and Engineering, University of Connecticut, Storrs, CT 06239, USA \\ ${ }^{2}$ Department of Chemical and Biomolecular Engineering, University of Connecticut, Storrs, CT 06239, USA \\ ${ }^{3}$ School of Materials and Manchester Institute of Biotechnology, University of Manchester, 131 Princess Street, \\ Manchester M1 7DN, UK
}

Received: 13 February 2017
Accepted: 13 February 2017
Published online:
27 February 2017
C) Springer Science+Business
Media New York 2017

Wei Zhang has published over 13000 research articles, according to Clarivate Analytics' Web of Science, making him one of the most prolific researchers in the world [1]. His papers from 2015 and 2016 have already been cited more than 9000 times. His impressive metrics are helped, of course, by his name being shared by about 300000 others in China. This is an extreme example, but it's worth remembering that even if you're one in a million, there are another 7000 like you.

Uniquely identifying researchers is part of the reason that the Journal of Materials Science has joined other leading journals in requiring authors to use the Open Researcher and Contributor iD (ORCID) system. Before submitting a manuscript to the Journal, corresponding authors must be registered with ORCID. The employment and publications ('works') sections must be publicly viewable. And before we can accept a manuscript, we require ORCID information for every author on the paper. Practicing what we preach, we Editors all have a valid ORCID (Table 1).

It's straightforward to registering for an ORCID iD. (We are aware of the redundancy in the phrase; it's like 'PIN numbers' and 'ATM machines'.) Signing up at orcid.org takes less than a minute. It's easy to then populate your list of publications by linking your profile to existing systems like the ResearcherID, Scopus Author ID and Google Scholar.

Since there are already several author identifier services available, why have we chosen to require ORCID iDs? Many of the benefits for authors are already well argued in a 2012 Nature news article [1], the opening of which we shamelessly aped in this editorial. First, ORCID is run by a not-for-profit company, in contrast to the existing systems we noted, with a rotating board and more than 600 member organisations, including our publisher.

Address correspondence to E-mail: cbarrycarter@gmail.com; URL: http:/ /www.cbarrycarter.com,

http://blanfordgroup.com/ 
Table 1 The ORCID identifiers for the Journal's editors

\begin{tabular}{ll}
\hline Editor & ORCID \\
\hline Mark Aindow & $0000-0001-6617-1409$ \\
Pamir Alpay & $0000-0003-4480-1558$ \\
Raymundo Arroyave & $0000-0001-7548-8686$ \\
Mark Bissett & $0000-0002-8908-7960$ \\
Chris Blanford & $0000-0002-0112-7818$ \\
Pedro Camargo & $0000-0002-7815-7919$ \\
Dave Cann & $0000-0003-2138-1933$ \\
Barry Carter & $0000-0003-4251-9102$ \\
Chris Cornelius & $0000-0002-1401-6711$ \\
Steve Eichhorn & $0000-0003-4101-273 X$ \\
Jan Evans-Freeman & $0000-0002-3946-086 X$ \\
Jaime Grunlan & $0000-0001-5241-9741$ \\
Kevin Jones & $0000-0003-0195-5477$ \\
Maude Jimenez & $0000-0002-0372-1503$ \\
Doug Medlin & $0000-0002-4613-1335$ \\
Philip Nash & $0000-0003-2975-8512$ \\
Grant Norton & $0000-0003-0434-0064$ \\
Ravi Ravishankar & $0000-0003-0012-046 X$ \\
Annela Seddon & $0000-0002-5794-8500$ \\
Brian Sheldon & $0000-0002-9593-891 X$ \\
Greg Rutledge & $0000-0001-8137-1732$ \\
\hline
\end{tabular}

Second, it saves researchers time by getting rid of the need to re-enter the same data on many websites. The data in ORCID can be linked with other systems and workflows through their application programming interface (API). Third, linking together multiple systems creates a 'researcher-centric view of science' [1] and can be used to collate article-level and 'alternative' impact metrics like television appearances and tweets. (This is something we hinted at in a previous editorial on journal impact factors [2].)

Now to the main reason that we, the Editors of the Journal of Materials Science, are requiring an ORCID iD from every author: like our plagiarism checking [3], it's part of our commitment to ethical scientific publishing.

We have known for many years now that fictitious authors are sometimes included in the list of authors. Our most notorious case came from a large wellknown North American university. The author's address was actually in the Athletics Department, rather than Materials Science and Engineering, and the current Dean can find no record of his ever attending the university, let alone that Department. We have a list of the papers that he published (fortunately journals other than the Journal of Materials
Science). All the co-authors of those papers will know that he is a fiction, as do the authors who recommended him as a reviewer! And yes, 'Mike', those papers are all online and your co-authors should know that this blot on their reputations is known, and will one day bite them.

Would the ORCID system have caught such a fraud? Well, 'Mike' could have registered and obtained an ORCID iD and populated it in a believable way. The hope is that the 'co-authors' would be reluctant to go the extra step of registering such a fictitious 'colleague'. ORCID do not curate or control the data, but they do have published transparent procedures to verify and correct their data, including suspending accounts [4].

We hope that widespread use of the ORCID system will further ethical publication in two more ways.

First, this journal and others are increasingly seeing suspicious changes in the list of authors between 'revision' and 'acceptance'. These can be red flags for purchased authorship. A post on Retraction Watch last year listed seven indicators, such as 'an absence of previous publications by one or more co-authors in the field of the manuscript' [5]. Requiring ORCIDs will make this fraudulent behavior easier to police. Changes in authorship in at revision (and after acceptance) are scrutinized by the editorial office, may lead to 'acceptance' changing to 'rejection', and may be escalated to our publisher's ethics team.

Second-and this will take more time to correctour fictitious friend 'Mike' was also regularly suggested as a referee! Peer-review rings and cases of authors reviewing their own work under an alias are rife [6]. We won't use alberteinstein1403@gmail.com as a referee but you can readily imagine variations on this theme. When reviewers are also required to have an ORCID iD there will be even more protection.

ORCID is the de facto standard unique researcher identifier. It clearly has reached 'critical mass' with over 3 million identifiers already registered, including over 300 Wei Zhangs. The Journal of Materials Science is proud to embrace this tool.

\section{References}

[1] Butler D (2012) Scientists: your number is up. Nature 485:564. doi:10.1038/485564a 
[2] Blanford CF (2016) Impact factors, citation distributions and journal stratification. J Mater Sci 51:10319-10322. doi:10. 1007/s10853-016-0285-X

[3] Carter CB, Blanford CF (2016) Plagiarism and detection. J Mater Sci 51:7047-7048. doi:10.1007/s10853-016-0004-7

[4] Haake L (2012) ORCID dispute procedures. https://orcid.org/ orcid-dispute-procedures. Accessed 8 Feb 2017
[5] Mason P, Bernardez Sarria MS (2016) 7 signs a scientific paper's authorship was bought. http://retractionwatch.com/ 2016/10/24/seven-signs-a-paper-was-for-sale/. Accessed 8 Feb 2017

[6] Ferguson C, Marcus A, Oransky I (2014) Publishing: the peerreview scam. Nature 515:480-482. doi:10.1038/515480a 